\title{
Remote Sensing Monitoring and Effect Evaluation on Ecological Restoration of Heidaigou Coal Mining Area
}

\author{
Huang Dan \\ 1 State Key Laboratory of Resources and Environmental \\ Information System, Institute of Geographic Sciences and \\ Natural Resources Research, CAS \\ 2 University of Chinese Academy of Sciences \\ Beijing, China
}

\begin{abstract}
With the rapid development of society and economy, the increasing demands of coal resources not only caused the over-exploitation, but also damaged the ecological environments. So it is important to restore the mining areas, which largely means vegetation restoration. This paper takes Heidaigou mining area as the study area to get an idea of how to monitor and restore the Heidaigou mining area effectively. The data used in the research are Landsat images and CBERS images that taken from 2001 to 2010 between June and October. By analyzing the images of study area with the technologies of remote sensing and geographic information system, we get the interpreted images of typical surface features of Heidaigou mining area. The results show that the area of exposed soil of waste-dump is increasing in Heidaigou mining area, which means the intensity of exploitation is rising. Besides, the growing area of vegetation restoration shows that the intensity level of restoration is also ascending year after year in Heidaigou mining area.
\end{abstract}

Index Terms - Remote sensing; Heidaigou coal mine; waste of dump; vegetation restoration; ecological restoration monitoring

\section{INTRODUCTION}

Most of China's coal mines are located in arid or semiarid areas, where vegetation is very sparse and the ecological environment condition is poor. Soil erosion and land desertification is one of the most prominent environmental problems that China's coal mining areas are facing ${ }^{[1]}$.

Nowadays, the lands occupied by waste-dumps in mining area in our country are reaching to 16300 hectares(ha) ${ }^{[2]}$, which not only lead to a great waste of land resources, but also damage the vegetation on land surface badly. Besides, the flying ash of waste-dumps also pollutes the air and do harm to people living around. So it is urgent to restore the mining areas ecologically, which largely means vegetation restoration.

\section{STUDY AREA}

Heidaigou coal mine belongs to Junggar energy limited liability company which was set up in1999.It was located in Xuejiawan town, Jungar Banner, Ordos City, Inner Mongolia Autonomous Region. The altitude of Heidaigou coal mine is

\author{
Liu Qingsheng \\ State Key Laboratory of Resources and Environmental \\ Information System, Institute of Geographic Sciences and \\ Natural Resources Research, CAS \\ Beijing, China
}

$1025-1302 \mathrm{~m}$, and the geographical coordinates is $111^{\circ}$ $16 ' 3.238$ "E, $39 \circ 49 ' 2.351 " N$. Heidaigou coal mine occupies a total area of 5124 ha, in which waste-dumps occupy more than $629 \mathrm{ha}^{[3]}$.

\section{DATA SOURCE AND DATA PREPROCESS}

According to the characteristics of study area, remote sensing images from 2001 to 2010 between June and October are studied as the source data in this paper. Data from 2001 to 2003 are recorded by ETM+ sensor of Landsat7, and the track number of satellite is 127-32. Data of 2004 and 2005 are recorded by CBERS, whose track number is 655. And data from 2006 to 2010 are recorded by TM sensor of Landsat-5 with No.127-32 track ${ }^{[4]}$. What should be noticed is that the data, recorded between June and October when plants grow best and the vegetation coverage rate reach to summit, are considered as the optimal data sources to have an accurate monitoring on the vegetation restoration.

In addition, preprocessing of the images should be done as the demand of the research, including the correction of radiometric calibration and atmospheric ${ }^{[5]}$, the geometric correction could be finished with the high-resolution images from Google Earth ${ }^{[6]}$. After corrections, resampling of the images with a quadratic spline function method is indispensable, and the error of total preprocess must be guaranteed less than 0.5 pixel.

\section{METHODS}

According to the visual interpretation method, the interpreted images of typical surface features in Heidaigou mining area can be achieved by using ENVI 4.7 and ArcMap 10 software. The typical surface features, including bare soil area of waste dump, vegetation restoration area of waste dump, coal gangue yard, coal mining pit, coal yard and mining area, are analyzed in this paper. Based on the analysis of the location and extent of these surface features, the ecological restoration effect of Heidaigou mining area is studied $^{[7,8]}$. Details can be described as follows:

(1) The mining area of 2010(Figure 1) is selected as the standard study zone, while others are cut with ENVI software in accordance with the image of 2010. 
(2) By using Arcmap, the interpreted maps of all typical surface features in study zone are analyzed and showed in Figure 2.

(3) Based on the interpreted maps, the areas of different surface features are calculated in Table 1, the percentages of vegetation restoration of waste dumps are calculated in Table 2 , and the trend is showed in Figure 3 and Figure 4.

(4) Proposals of ecological restoration are listed after the research on the current ecological condition of Heidaigou mining area.

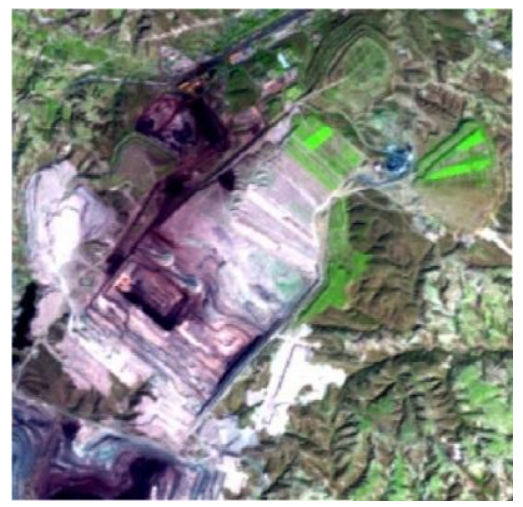

Fig.1 image of Heidaigou mining area in 2010

Tab.1 area of the surface features of Heidaigou mining area from 2001 to 2010 (ha)

\begin{tabular}{|c|c|c|c|c|c|}
\hline $\begin{array}{c}\text { Year } \\
\text { Area(ha) }\end{array}$ & 2001 & 2002 & 2003 & 2004 & 2005 \\
\hline $\begin{array}{c}\text { bare soil area } \\
\text { of waste dump }\end{array}$ & 483.66 & 528.64 & 665.43 & 912.92 & 1152.80 \\
\hline $\begin{array}{c}\text { vegetation } \\
\text { restoration } \\
\text { area of waste } \\
\text { dump }\end{array}$ & 80.92 & 99.81 & 95.99 & 149.26 & 179.86 \\
\hline $\begin{array}{c}\text { coal gangue } \\
\text { yard }\end{array}$ & 51.42 & 51.20 & 31.50 & 32.24 & 32.43 \\
\hline coal mining pit & 80.20 & 81.00 & 67.41 & 67.02 & 60.99 \\
\hline $\begin{array}{c}\text { coal yard } \\
\text { mining area }\end{array}$ & 12.90 & 7.58 & 17.34 & 15.61 & 19.13 \\
\hline \multicolumn{2}{|c|}{78.03} & 78.32 & 80.89 & 126.12 & 51.30 \\
\hline $\begin{array}{c}\text { Year } \\
\text { Area(ha) }\end{array}$ & 2006 & 2007 & 2008 & 2009 & 2010 \\
\hline $\begin{array}{c}\text { bare soil area } \\
\text { of waste dump }\end{array}$ & 1065.33 & 1146.77 & 1016.15 & 930.29 & 844.29 \\
\hline $\begin{array}{c}\text { vegetation } \\
\text { restoration } \\
\text { area of waste } \\
\text { dump }\end{array}$ & 179.35 & 185.72 & 303.66 & 376.50 & 590.11 \\
\hline $\begin{array}{c}\text { coal gangue } \\
\text { yard }\end{array}$ & 31.14 & 26.48 & 29.78 & 44.19 & 21.21 \\
\hline coal mining pit & 68.10 & 48.61 & 48.53 & 50.47 & 30.55 \\
\hline $\begin{array}{c}\text { coal yard } \\
\text { mining area }\end{array}$ & 158.72 & 177.91 & 333.68 & 350.45 & 374.00 \\
\hline
\end{tabular}

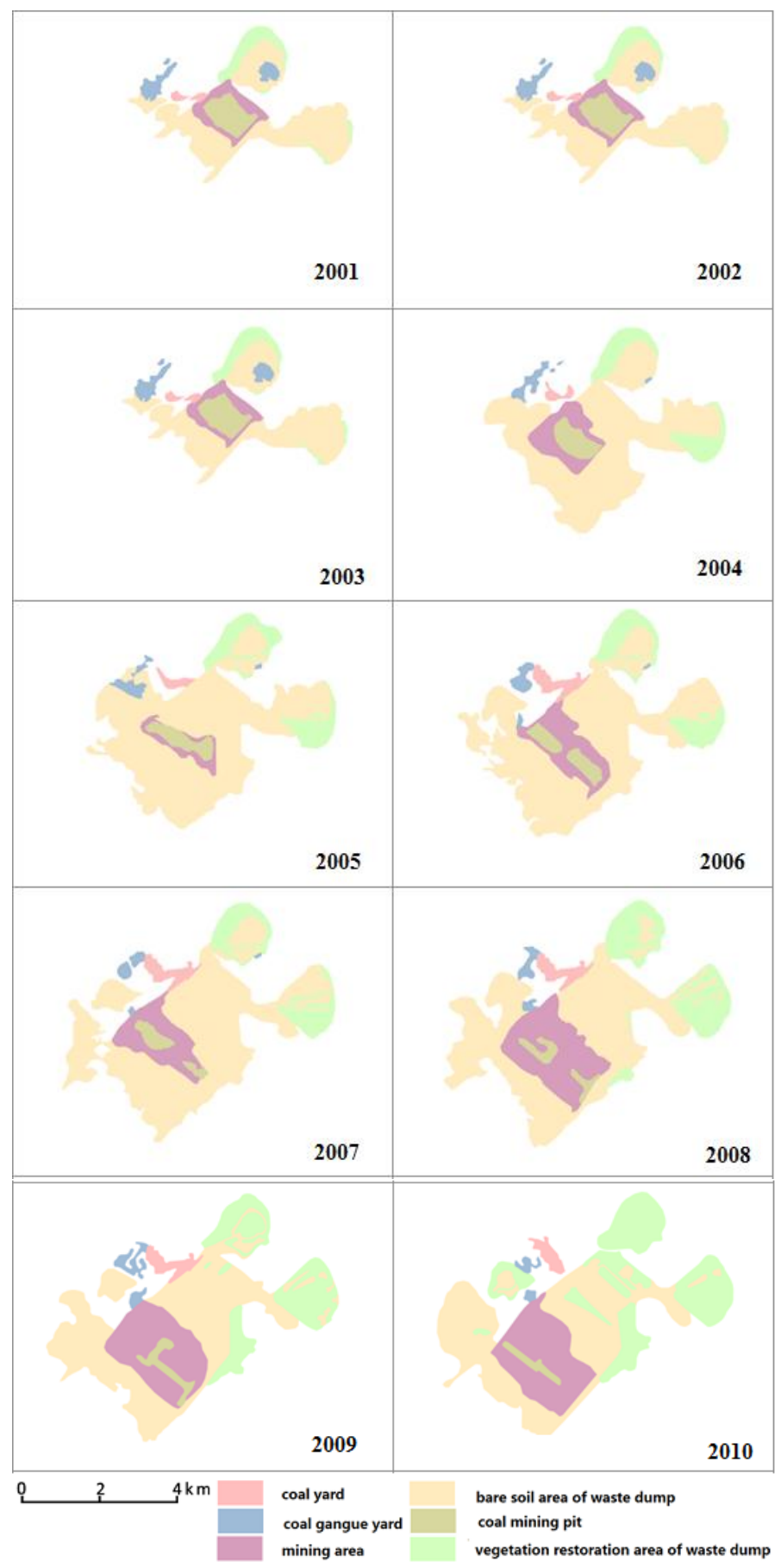

Fig.2 Interpreted images of Heidaigou mining area from2001 to 2010

Tab.2 Percentage of vegetation of Heidaigou mining area from 2001 to

\begin{tabular}{|c|c|c|c|c|c|}
\hline $\begin{array}{c}\text { Year } \\
\text { Percent }(\%)\end{array}$ & 2001 & 2002 & 2003 & 2004 & 2005 \\
\hline $\begin{array}{l}\text { Percent of vegetation } \\
\text { restoration area of } \\
\text { waste dump }\end{array}$ & 14.33 & 15.88 & 12.61 & 14.05 & 13.50 \\
\hline $\begin{array}{c}\text { Year } \\
\text { Percent }(\%)\end{array}$ & 2006 & 2007 & 2008 & 2009 & 2010 \\
\hline
\end{tabular}




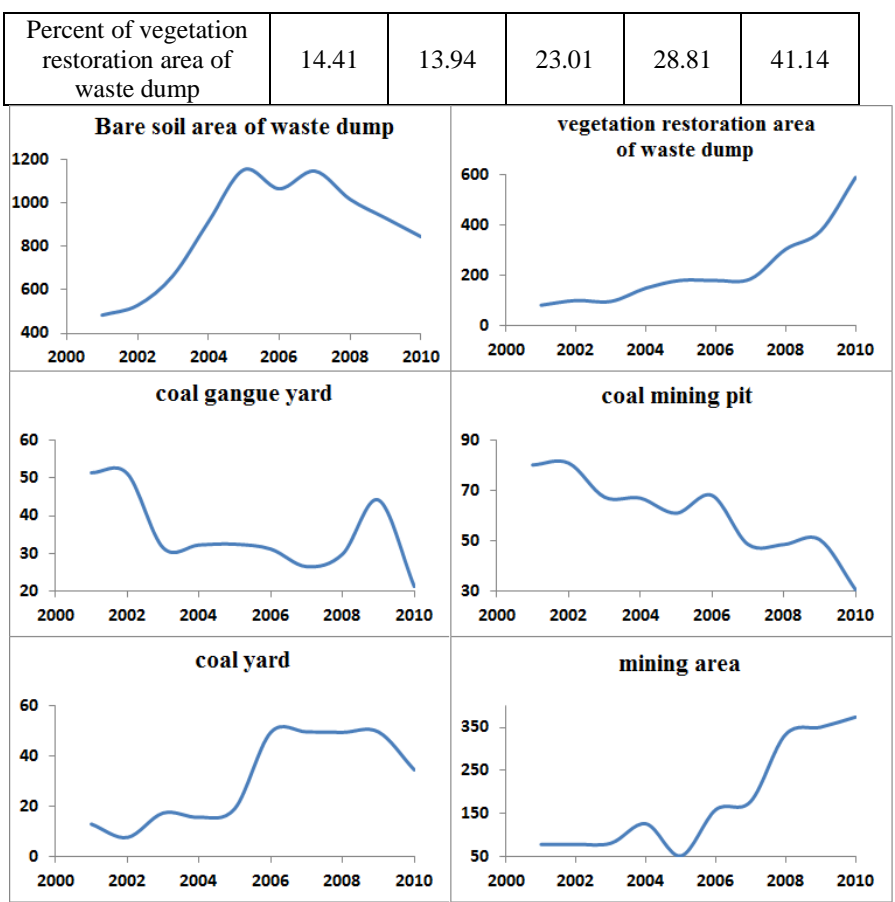

Fig.3 area diagrams of Heidaigou mining area from 2001 to 2010 (ha)

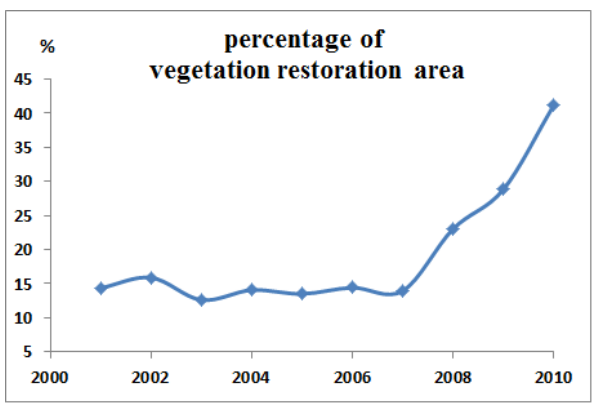

Fig.4 diagram of the percentage of vegetation of Heidaigou mining area from 2001 to 2010 (\%)

\section{CONCLUSIONS AND DISCUSSIONS}

The effect of ecological restoration in Heidaigou mining area can be evaluated based on the interpreted maps and scatter plots.

(1)The results show that the mining area and coal yards are getting bigger almost every year, so is the bare soil area of waste dumps during 2000 to 2010 . This trend means that the intensity of mining increases steadily. Besides, the bare soil area of waste dumps decrease since 2007, which may due to the increasing intensity level of vegetation restoration.

(2)In this decade, the area of coal gangue yard decreases, which means that some coal gangue yards have been earthed up and even been planted for the ecological restoration.

(3)The vegetation restoration area of waste dump continues to increases during the period. It can be attributed to the increasing strength of ecological restoration and the effect of restoration.

(4)Generally, the area of coal mining pit decreases these years, while intensity of mining is increasing. It can be concluded that the depth of coal mining pit is increasing, so is the volume of coal mining pit.

(5)It is easily to find an increasing trend in the percentage of the vegetation restoration area from Table 1 and Figure 3. This trend is clearly caused by manual intervention of vegetation restoration, and the restoration effect is distinguished. From the figure 4, the percentage of vegetation restoration area is only about $15 \%$ in 2001, while in 2010 the percentage is more than $41 \%$. A nearly $26 \%$ increase proves an obvious effect of ecological restoration. And the light decrease in 2003 and 2007 may be affected by the sudden enhancements of mining intensity or the poor growth of vegetation which influenced by external natural conditions.

(6) The plants grow better in yards carried out earlier, especially in aspect of ecosystem balance; and vegetation restoration situation in shady side is better than that in sunny side in the same yard, which may be influenced by the high evaporation and low soil moisture conservation capacity in sunny slope. In addition, vegetation recovers much faster in the yards re-earthed than other yards. To recover natural vegetation, re-earth is suggested to be done before planting.

What's more, something else can be deduced from the interpreted maps. The waste dumps in Heidaigou mining area are numbered as below(Figure 5).

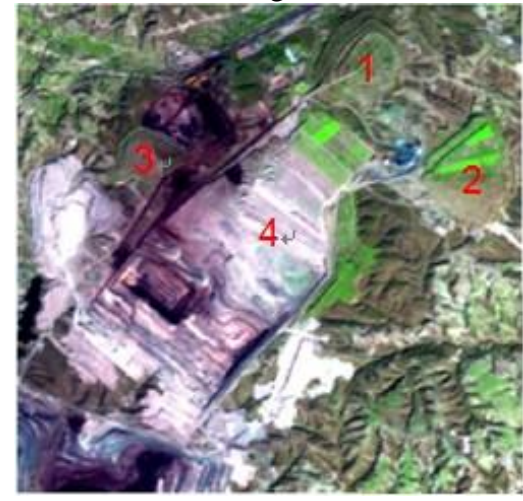

Fig. 5 waste dumps in Heidaigou mining area

No.1, No.2 and No.4 dumps have been earthed up in 1999; No.3 dump has begun to be earthed up in 2001, but not began to restore until 2008.

The extent and position of vegetation restoration area of No.1 dump kept steady from 1999 to 2004. Manual repair of No.1 dump started in 2005, artificial division of the regions could be obviously seen on the surface of No.1 dump, which are prepared for regulatory vegetation restoration. During the subsequent years, the vegetation restoration area of No.1 dump kept increasing. In 2010, the dump was completely covered by vegetation.

Starting in 2000, the area of No.2 dump increases significantly, so does the change in shape. The vegetation restoration of No. 2 dump began in 2000, but the repair area was small. However, the area of vegetation restoration has increased since 2004, and the vegetation area covered almost all the dump surface in 2010. 
In addition, No.1 dump is a bare soil waste dump, which also be used for stacking coal gangue until 2004 that the coal gangue yards on No.1 dump are earthed up.

The vegetation restoration of No.3 dump began from 2008 , but the vegetation on the surface is sparse. Starting in 2010 , the dump was surrounded by dense vegetation, but the area covered is not large.

No.4 dump is the largest in several dumps. The dump area has been increasing since 1999. Vegetation restoration of No.4 dump was started in 2008, and the vegetation area was located in the southeast edge of the dump. In following years, the dump repair area keeps increasing, so does the extent of coverage. The dump achieves maximum restoration area in 2010. The restoration area mainly distribute in the southeast and northeast edge of the dump.

The development of Heidaigou mine leads to lots of ecological and environmental problems, such as water pollution, air pollution of flying ash, noise pollution, surface subsidence and waste of land. Therefore, it is necessary and eager to take preventive and treatment measures:

(1)Ecological restoration in mining needs on the basis of the principle that mineral resources development and ecological environment protection must be balanced. That means vegetation recovery measures can be simply used during mining, such as temporary sheathe of earth.

(2)Strengthening the education and improving worker's environmental awareness in mining area are effective to reduce the ecological damage. With the help of policies, laws and regulations, a strict management of ecological restoration is efficient.

(3)It is helpful to introduce advanced technologies in the mining process and improve the utilization of mineral resources. And a dynamic monitoring system should be established to monitor the ecological environment in mining area in real time.

(4)Plants with features of growing fast, higher cover degree, resistant to pollution and drought, strong adaptability and higher survival rate, are conducive to soil improvement and native species protection, such as acacia, alfalfa, licorice, ipomoea purpurea and teff. Besides, planting should be in early spring, and autumn for a better growth ${ }^{[9]}$.

(5)Soil fertility is one of the most important factors in vegetation restoration. As the poor soil fertility in mining area, the survival rate of plants is very low. Using artificial fertilization and planting legumes massively first in early stage of the reclamation are desirable to fertilize the soil ${ }^{[10]}$.

\section{ACKNOWLEDGEMENTS}

This research work was jointly supported by a grant from Special Environmental Scientific Research Fund for public Welfare (Project No. 201109043) and a grant from the Research Fund of Field Station of IGSNRR, CAS.

\section{REFERENCES}

[1] Fan Yinghong, Lu Zhaohua, Cheng Jianlong etc. Major Ecological and Environmental Problems and Ecological
Reconstruction Technologies of Coal Mining Areas in China [J].Acta Ecologica Sinica.2003, (10).

[2] Wei Zhongyi, Bai Zhongke. Runoff dispersing concept and its measures of Erosion control in Large scale open-pit dumps. [J].Journal of China Coal Society,2003,(5).

[3] Chang Jun, Wang Jiantong, Liu Yang. Land Reclamation Research in Heidaigou Coal Mining Area. [J].Shandong Coal Science and Technology,2011,(3):94-95. Yao Minjuan, Zhang Shuli, Li Qingfeng etc. Effects of Different Vegetation Types on Soil Moisture of Dumping Site in Heidaigou Opencast Mine_-Vertical Dynamic of Soil Water Content. [J].Inner Mongolia Environmental Sciences,2011,23(1-2):29-32.

[4] Zhao Yingshi. Principles and Methods of Remote Sensing Application and Analysis.[M].Beijing: Science Press, 2003:222 - 241.

[5] Zhu Shaopan, Chen Yu. Methods for Atmospheric Radiation Correction.[J].Geospatial Information, 2010,8 ( 1 ) :113-116.

[6] Tang Hairong, Wu Yirong, Xiang Maosheng etc. Study on Geometric Correction Methods of Landsat 7 Images.[J].Jourmal of Remote Sensing, 2005,9(1):58-63.

[7] Li Jiangfeng. Study on Ecological Restoration and Effect Monitoring in the Iron Ore Stope of Beijing Shougang Co.Ltd. [D].Beijing: Beijing Forestry University,2007.

[8] Zhou Chunlan. Study on Monitoring of Mine Ecological Environment Based on RS,GIS\&GPS - Baoding Coal Mine in Panzhihua as an Example.[D].Chengdu: Chengdu University of Technology,2009.

[9] Liao Chenghao. Study on Ecological Effects of Mining Landscape and Ecological Restoration in Yangquan Coal Mining Region.[D].Beijing: Tsinghua Universitu,2009.

[10]He Liang. Synthetic Evaluation of Ecological Environment Influence Ecological Environmental Protection and Ecology Repair Countermeasures for Open-Pit Mining. [D].Xian: Northwest University, 2010. 